\title{
Effect of changing various parameters on stress distribution in mini-screws and surrounding alveolar bone :A three- dimensional finite element analysis
}

\author{
Ayman Mohamed Sadek ${ }^{1}$ Ibrahim MazenNegm ${ }^{2}$ KhaledAboulazm $^{3}$
}

Aim: The purpose of the study was to clarify and evaluate the effects of various force magnitudes and mini-screw length, diameter and insertion angle on the stress distribution of the mini-screw and the surrounding bone utilizing a three dimensional finite element analysis. Methods: We created a three dimensional finite element model simulating various clinical situations where mini-screws with different diameters (1.5 and $2 \mathrm{~mm}$ ), lengths (9, 11 and $13 \mathrm{~mm})$ and insertion angles $\left(45^{\circ}\right.$ and $\left.90^{\circ}\right)$ were utilized under various force magnitudes (200 and $250 \mathrm{gm})$. The resultant deformations and stresses from the applied loading were analyzed with a 3D FEM according to maximum values of total deformations and Von Mises stress. Results: The Von Mises stresses in 6oth the mini-screw and the cortical bone in obliquely inserted $1.5 \mathrm{~mm}$ diameter screws with $200 \mathrm{gm}$ and 250gm force were higher than those with $2 \mathrm{~mm}$ diameter screws. The Von Mises stresses in the spongy bone in 6oth the vertically and obliquely inserted 1.5 and $2 \mathrm{~mm}$ diameter screws with 200gm and 250gm force were higher with the $2 \mathrm{~mm}$ diameter screws. The maximum compressive stress and equivalent micro-strain in cortical bone was evident with screw dimensions $13 \mathrm{~mm}$ length and $2 \mathrm{~mm}$ diameter under an oblique force magnitude of $250 \mathrm{gm}$. The Von Mises stresses in the spongy bone in obliquely inserted 1.5 and 2 $\mathrm{mm}$ diameter screws with $200 \mathrm{gm}$ and $250 \mathrm{gm}$ force were higher with the $2 \mathrm{~mm}$ diameter screws The maximum stress (Von Mises) generated in the miniscrew and cortical bone in all the simulated finite element models was 72.77 and $13.52 \mathrm{MPa}$ respectively. Conclusion: Increase in the mini-screw diameter with both vertical and oblique insertion reduced the deformations and stresses within the mini-screw and cortical bone but increased the deformations and stresses within the spongy bone. Increase in the mini-screw length with vertical insertion had negligible effect. The deformation and stress values within the cortical bone were higher in oblique insertion than vertical insertion with both (200 and $250 \mathrm{gm}$ ) force.

\section{Introduction}

Orthodontic mini-screws are increasingly used by orthodontists to provide temporary skeletal anchorage during orthodontic treatment this is because they offer additional advantages over conventional types of anchorage. In traditional orthodontic treatment, extraoral appliances such as headgear and various intraoral appliances are utilized to prevent anchorage loss. However lack of patient compliance in case of extraoral anchorage, and in some situations of missing or periodontal affected teeth that are strategic for intraoral anchorage, the utilization of these appliances is compromised.

\footnotetext{
${ }^{1}$ Assistant Research Lecturer of Orthodontics, National Research Center. Egypt

2 Assistant Professor of Orthodontics, Faculty of Dentistry, Ain Shams University.Egypt

${ }^{3}$ Assistant Professor, Department of Orthodontics, School of Dentistry, Pharos University, Alexandria,Egypt
} 
The orthodontic mini-screws offers several advantages, including small size, easy surgical procedure, minimal anatomic limitations which enable them to be placed in various sites without damaging any anatomical structures, easy insertion and removal with minimal trauma, and the ability of immediate loading after implantation, in addition to their relatively low cost. ${ }^{1,2}$

However, the mini-screw success rate in clinical practice has been reported to range from $83.9 \%$ to $93.3 \%{ }^{3,4}$.It was found that several factors influence their success and stability like miniscrew length, diameter ${ }^{5}$, design (tapered or cylindrical $)^{6}$ and surface treatment in addition to force magnitude $e^{7,8}$, insertion angle and torque ${ }^{9,10}$, implantation location, root proximity, soft-tissue characteristics.

On the other hand, factors identified as causing failure include inflammation, infection, nonkeratinized implant sites, and small size mini-screws, in addition to reliance on patient compliance in hygiene measures and application of intermaxillary elastics when needed. ${ }^{6}$

Kyung et al. ${ }^{11}$ recommended mini-screw insertion at angles of $30^{\circ}$ to $40^{\circ}$ in-order to avoid root injury, rather than perpendicular to the bone surface. Whereas previous studies suggested an insertion angle between $50^{\circ}$ and $70^{\circ}$ to achieve greater mini-screw stability under various loading conditions. ${ }^{12,13}$ Other researches, reported that inserting mini-screws at a $90^{\circ}$ angle to the bone surface decreases the stress concentration, whereas mini-screws at angles less than $90^{\circ}$ to the alveolar surface did not provide ad- vantages as regard to anchorage resistance force. ${ }^{9,10,14}$

Finite element analysis (FEA) is a noninvasive computer-based numerical simulation technique that is widely used for analyze, predicting, and forecast the biomechanical behavior of object movements. FEA provides the optimal assessment for the physical response to a mechanical stimulus and permits the study of different loading conditions.

The successful use of mini-screws in various applications demands a full understanding of their biomechanical performance in conjunction to their surrounding bone. Therefore, the FEA was utilized to better understand the stresses generated with different combinations of mini-screws sizes and angles of insertion.

The purpose of the study was to clarify and evaluate the effects of various force magnitudes and mini-screw length, diameter and insertion angle on the stress distribution of the mini-screw and the surrounding bone utilizing a three dimensional finite element analysis.

\section{Materials and Methods}

This finite element study simulated clinical situations where mini-screws with different diameters (1.5 and $2 \mathrm{~mm}$ ), lengths (9, 11 and $13 \mathrm{~mm}$ ) and insertion angles $\left(45^{\circ}\right.$ and $\left.90^{\circ}\right)$ were utilized under various force magnitudes (200 and 250gm).

I. Materials: 
The standard MONDEAL LOMAS (Medical Systems, Muhlheim, Germany)mini-screw type was chosen for this study due to the following advantages; (i) The denser pitch design and increased thread depth that ensured maximum anchorage. (ii) The self-drilling tip of the screw with its sharp threaded flanks provided easy cutting within the bone. In addition, to special surface treatment for the screw called anodization process (Anodurit $($ ) ) to provide a higher bending fatigue strength and lessen surface contamination for screw.

A three dimensional solid modeling software (Inventor professional version 8) was utilized for modeling the mini-screw with its various diameters and lengths (1.5 and $2.0 \mathrm{~mm})(9.0,11.0$, and $13.0 \mathrm{~mm})$ respectively. Whereas a three dimensional finite element analysis (FEA) software (Ansys version 14.0Inc., Canonsburg, PA, USA) was utilized for modeling the cortical and spongy bone assembly. The server upon which these programs were ran was, Workstation HP (ProLaint ML150, with Intel Xeon $3.2 \mathrm{GHz}$ processors with $1 \mathrm{MB}$ L2 cache, $8 \mathrm{~GB}$ RAM).

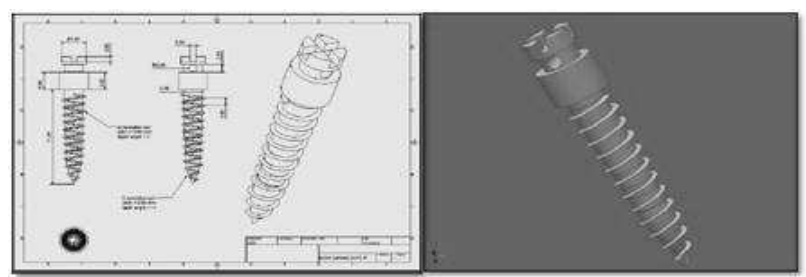

Figure 1: Sample of screw on the Inventor screen
II. Method:

*Construction of geometrical test model incorporated the miniscrew model which was created on Autodesk Inventor Version (8) (Autodesk Inc., San Rafael, CA, USA) according to the manufacturers dimensions and design as illustrated in figure 1 .

The cortical and spongy bone model were simulated as a parallelogram where the cortical bone dimensions were $(20 \mathrm{~mm}$ length, $20 \mathrm{~mm}$ width, and $2 \mathrm{~mm}$ height), whereas the spongy bone dimensions were $(20 \mathrm{~mm}$ length, $20 \mathrm{~mm}$ width, and $13 \mathrm{~mm}$ height).

The assembly of the mini-screw within the bone model was founded on subtracting the volume of the minis-crew model from both the cortical and spongy bone models according to the Boolean operation. The miniscrew model was then incorporated into the bone model in ANSYS* environment on the assumption of complete osseointegration. In this study the bone model was considered a solid type therefore the selected element types were the tetrahedral and brick. In this study both the mini-screw and bone (cortical and spongy) were assumed to be linearly elastic,homogeneous, and isotropic (thus having identical properties in all three dimensional directions) materials. For easier prediction of material behavior all loadings were in a linear range under static loading. The material properties of each different component representing the model were then assigned into the program. The linear static stress/strain analysis needed the definition of two essential parameters the Elastic 
(Young's) modulus and Poisson's Ratio for each component incorporated within the assembly which are shown in table 1 . All in- terfaces between the mini-screws and bone (cortical and spongy) were assumed to be bonded due to complete ossteoinegration

Table 1: Material properties

\begin{tabular}{|c|c|c|}
\hline Material & Young's Modulus & Poisson's ratio \\
& {$[\mathrm{MPa}]$} & \\
\hline Screw (Titanium) & 110,000 & 0.34 \\
\hline Spongy bone & 13,700 & 0.35 \\
\hline Cortical bone & 1300 & 0.35 \\
\hline
\end{tabular}

In this study the mesh generation involved dividing the constructed geometrical model (mini-screw and bone) into numerous small tetrahedral and brick finite elements. The smaller the elements the more precise, refined and accurate are the results. The solution functions obtained from all the elements compromising the mesh were combined together to calculate a solution to the whole body.

Twelve meshed models were required in order to test all the possible combinations of the mini-screws (length, diameter and insertion angle) under the various loading (200 and $250 \mathrm{gms}$ ), which are listed in table 2 . The following step was applying the structural load and constraints. A full constraint was used to simulate the boundary condition. Restriction of the boundary condition was mandatory in order to prevent the body from floating, rotating, and translating. This was performed by fixing the contouring lines of the cortical and spongy bone geometries figure.

All the various model combinations incorporating the screw and bone were subjected to loads of 200 and 250 gms with a $30^{\circ}$ angle to the horizontal plane table 3 . In order to mimic the solution functions for the resultant stresses a linear static analysis was made on a work station* using commercial multipurpose finite element software package (ANSYS version 14.0). The resultant deformations and stresses from the applied load- 
ing were collected in tables and figures according to maximum values of total deformations and Von Mises stress.

In our study the results were based on the total deformation $\left(\mathrm{U}_{\text {sum }}\right)$ and the Von Mises stress $\left(\mathrm{S}_{\mathrm{von}}\right)$ values. In order to calculate the microstrain in cortical bone the maximum compressive stress $\left(\mathrm{S}_{3}\right)$ was used. This was calculated in accordance to the formula (microstrain $=\mathrm{S}_{3} \times 72$ ).
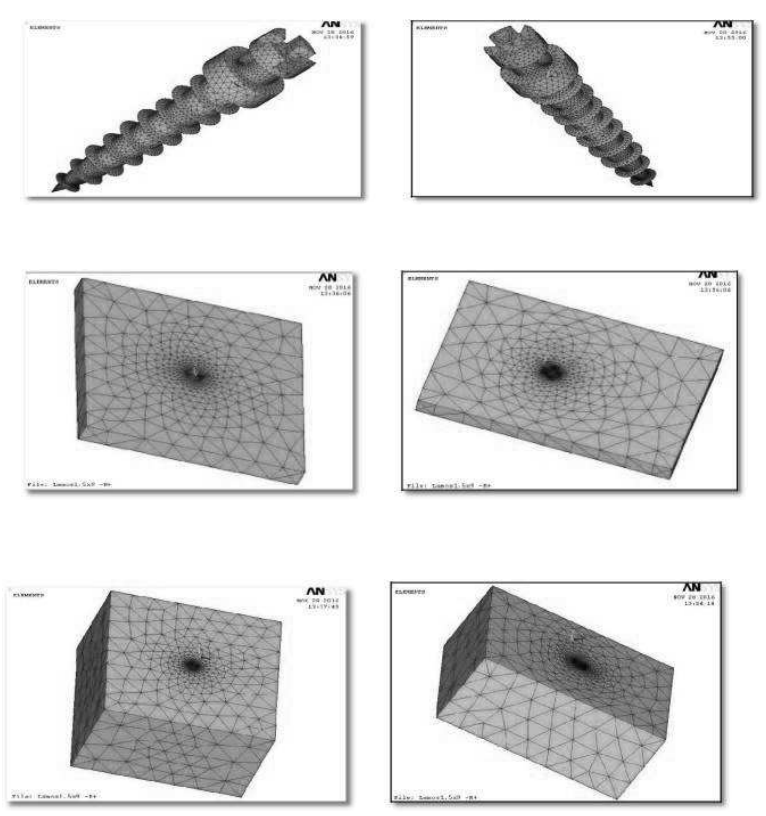

Figure 2: Model components after meshing (a) screw $1.5 \times 9.0$, (b) screw 2.0x11.0, (c) cortical bone with vertical screw hole, (d) cortical bone with oblique screw hole, (e) spongy bone with vertical screw hole, (f) spongy bone with oblique screw hole.
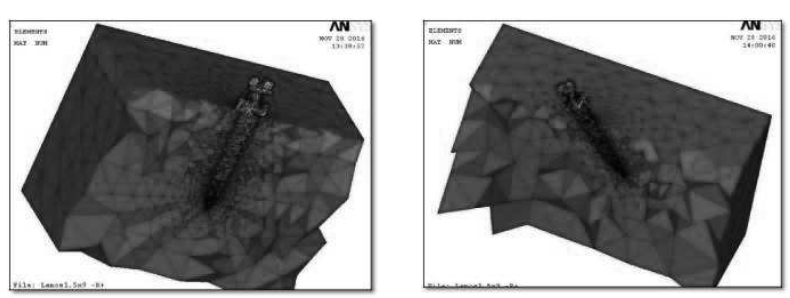

Figure 3: Sample of a complete longitudinal cut section in finite element models for the (a) vertical and (b) oblique screw.

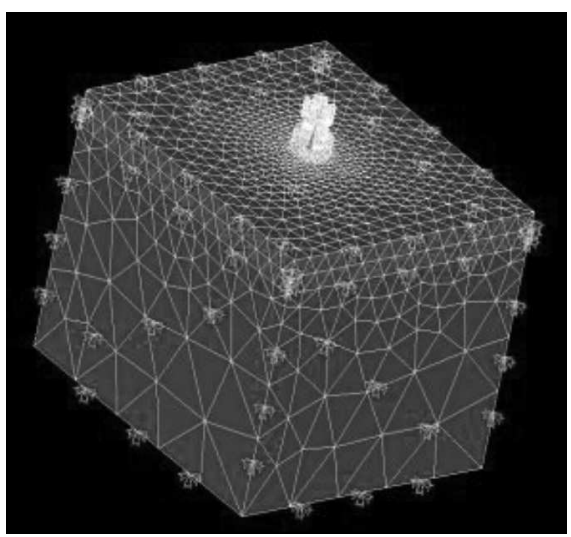

Figure 4: Finite element mesh assembly illustrating boundary constraints. 
Table 2 Mesh density

\begin{tabular}{|c|c|c|}
\hline Volume & Number of Nodes & Number of Elements \\
\hline \multicolumn{3}{|l|}{ Model \#1: $1.5 \times 9.0$ - vertical } \\
\hline Cortical bone & 887 & 8,729 \\
\hline Cancellous bone & 8,408 & 59,043 \\
\hline Screw & 5,712 & 45,794 \\
\hline \multicolumn{3}{|l|}{ Model \#2: $1.5 \times 11.0$ - vertical } \\
\hline Cortical bone & 1,347 & 12,119 \\
\hline Cancellous bone & 9,784 & 69,192 \\
\hline Screw & 7,007 & 55,954 \\
\hline \multicolumn{3}{|l|}{ Model \#3: $1.5 \times 13.0$ - vertical } \\
\hline Cortical bone & 938 & 9,140 \\
\hline Cancellous bone & 9,976 & 72,097 \\
\hline Screw & 7,652 & 61,094 \\
\hline \multicolumn{3}{|l|}{ Model \#4: 2.0x9.0 - vertical } \\
\hline Cortical bone & 819 & 8,242 \\
\hline Cancellous bone & 7,782 & 55,196 \\
\hline Screw & 5,353 & 43,266 \\
\hline Model \#5: 2.0x11.0 - vertical & & \\
\hline
\end{tabular}




\begin{tabular}{|c|c|c|}
\hline Cortical bone & 773 & 8,036 \\
\hline Cancellous bone & 7,793 & 56,769 \\
\hline Screw & 6,149 & 49,433 \\
\hline \multicolumn{3}{|c|}{ Model \#6: 2.0x13.0 - vertical } \\
\hline Cortical bone & 777 & 8,050 \\
\hline Cancellous bone & 7,848 & 58,959 \\
\hline Screw & 7,165 & 57,435 \\
\hline \multicolumn{3}{|c|}{ Model \#7: 1.5x9.0 - Oblique } \\
\hline Cortical bone & 1,599 & 15,039 \\
\hline Cancellous bone & 5,086 & 37,418 \\
\hline Screw & 7,357 & 57,449 \\
\hline \multicolumn{3}{|c|}{ Model \#8: 1.5x11.0 - Oblique } \\
\hline Cortical bone & 1,903 & 17,354 \\
\hline Cancellous bone & 9,491 & 67,683 \\
\hline Screw & 8,761 & 68,322 \\
\hline \multicolumn{3}{|c|}{ Model \#9: 1.5x13.0 - Oblique } \\
\hline Cortical bone & 1,942 & 18,777 \\
\hline Cancellous bone & 9,724 & 74,606 \\
\hline
\end{tabular}




\begin{tabular}{|c|c|c|}
\hline Screw & 10,138 & 78,361 \\
\hline \multicolumn{3}{|c|}{ Model \#10: 2.0x9.0 - Oblique } \\
\hline Cortical bone & 2,102 & 19,554 \\
\hline Cancellous bone & 9,965 & 76,587 \\
\hline Screw & 11,002 & 79,023 \\
\hline \multicolumn{3}{|c|}{ Model \#11: 2.0x11.0 - Oblique } \\
\hline Cortical bone & 2,189 & 19,775 \\
\hline Cancellous bone & 10,461 & 81,146 \\
\hline Screw & 11,095 & 85,268 \\
\hline \multicolumn{3}{|c|}{ Model \#12: 2.0x13.0 - Oblique } \\
\hline Cortical bone & 2,304 & 20,087 \\
\hline Cancellous bone & 10,723 & 82,214 \\
\hline Screw & 11,134 & 88,573 \\
\hline
\end{tabular}




\begin{tabular}{|c|c|c|c|c|c|c|c|c|c|}
\hline & & Min & crew & & & & Min & crew & \\
\hline Runs & $\begin{array}{l}\text { Load } \\
\text { (gm) }\end{array}$ & $\begin{array}{l}\text { Position } \\
90^{\circ}\end{array}$ & Diameter & Length & Runs & $\begin{array}{l}\text { Load } \\
\text { (gm) }\end{array}$ & $\begin{array}{c}\text { Position } \\
45^{\circ}\end{array}$ & Diameter & Length \\
\hline 1 & 200 & Vertically & 1.5 & 9 & 13 & 200 & Oblique & 1.5 & 9 \\
\hline 2 & 250 & Vertically & 1.5 & 9 & 14 & 250 & Oblique & 1.5 & 9 \\
\hline 3 & 200 & Vertically & 1.5 & 11 & 15 & 200 & Oblique & 1.5 & 11 \\
\hline 4 & 250 & Vertically & 1.5 & 11 & 16 & 250 & Oblique & 1.5 & 11 \\
\hline 5 & 200 & Vertically & 1.5 & 13 & 17 & 200 & Oblique & 1.5 & 13 \\
\hline 6 & 250 & Vertically & 1.5 & 13 & 18 & 250 & Oblique & 1.5 & 13 \\
\hline 7 & 200 & Vertically & 2 & 9 & 19 & 200 & Oblique & 2 & 9 \\
\hline 8 & 250 & Vertically & 2 & 9 & 20 & 250 & Oblique & 2 & 9 \\
\hline 9 & 200 & Vertically & 2 & 11 & 21 & 200 & Oblique & 2 & 11 \\
\hline 10 & 250 & Vertically & 2 & 11 & 22 & 250 & Oblique & 2 & 11 \\
\hline 11 & 200 & Vertically & 2 & 13 & 23 & 200 & Oblique & 2 & 13 \\
\hline 12 & 250 & Vertically & 2 & 13 & 24 & 250 & Oblique & 2 & 13 \\
\hline
\end{tabular}

Table 3: The twenty four finite element runs. 


\section{RESULTS}

The Von Mises stresses in vertically inserted $1.5 \mathrm{~mm}$ diameter screws with $200 \mathrm{gm}$ and $250 \mathrm{gm}$ force were higher than those with 2 $\mathrm{mm}$ diameter screws as illustrated in figure 5 $(\mathrm{a}-\mathrm{b})$ respectively.
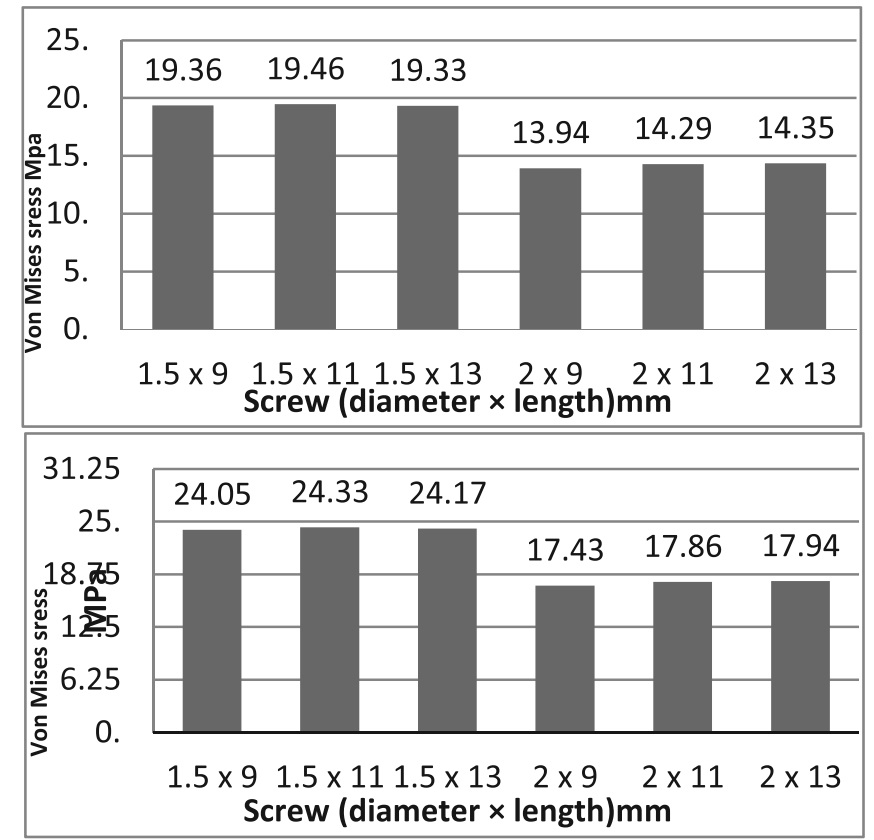

Figure 5(a-b) Vertically inserted screws with 200 and $250 \mathrm{gm}$ force (Von Mises stresses) in mini-screws

The Von Mises stresses in obliquely inserted $1.5 \mathrm{~mm}$ diameter screws with $250 \mathrm{gm}$ force were higher than those with $2 \mathrm{~mm}$ diameter screws as illustrated in figure $6(a-b)$ respectively.

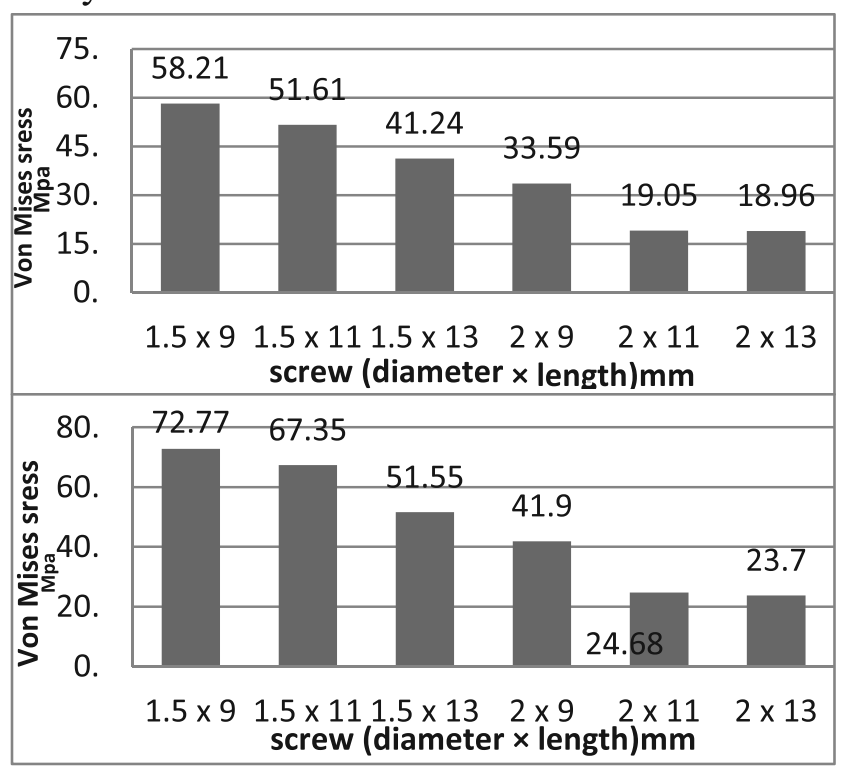

Figure 6(a-b) Obliquely inserted screws with 200 and $250 \mathrm{gm}$ force (Von Mises stress) in mini-screws

The Von Mises stresses in cortical bone in vertically inserted $2 \mathrm{~mm}$ diameter screws with $200 \mathrm{gm}$ and $250 \mathrm{gm}$ force were nearly the same as those with $1.5 \mathrm{~mm}$ diameter screws as illustrated in figure 7 (a-b) respec-
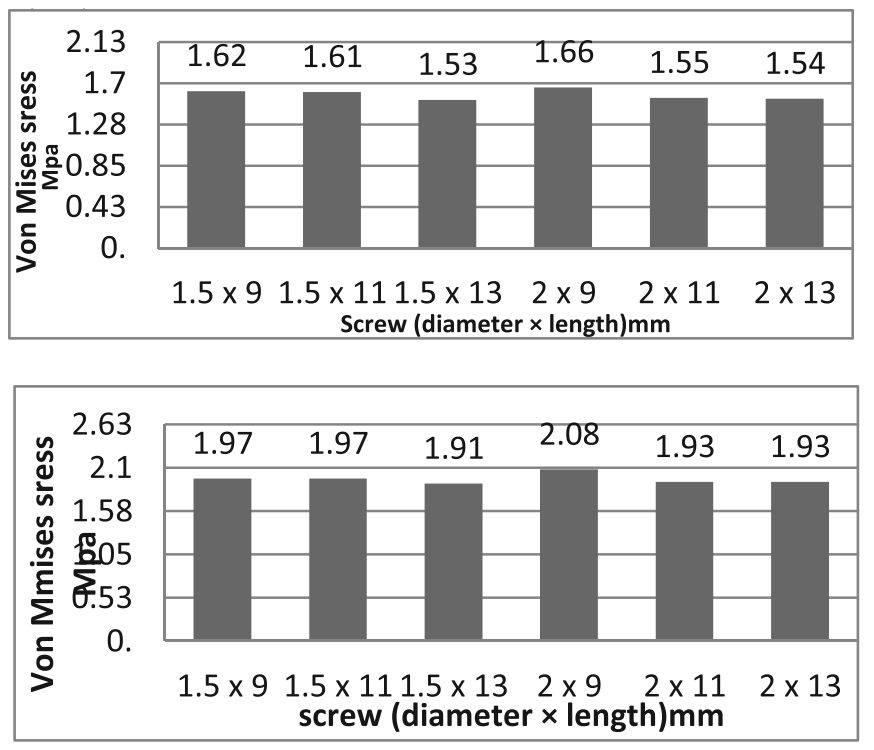

Figure 7(a-b) Vertically inserted screws with 200 and $250 \mathrm{gm}$ force (Von Mises stresses) in cortical bone

The Von Mises stresses in the cortical bone in obliquely inserted $1.5 \mathrm{~mm}$ diameter screws with $200 \mathrm{gm}$ and $250 \mathrm{gm}$ force were higher than those with $2 \mathrm{~mm}$ diameter screws as illustrated in figure $8(a-b)$ respectively.
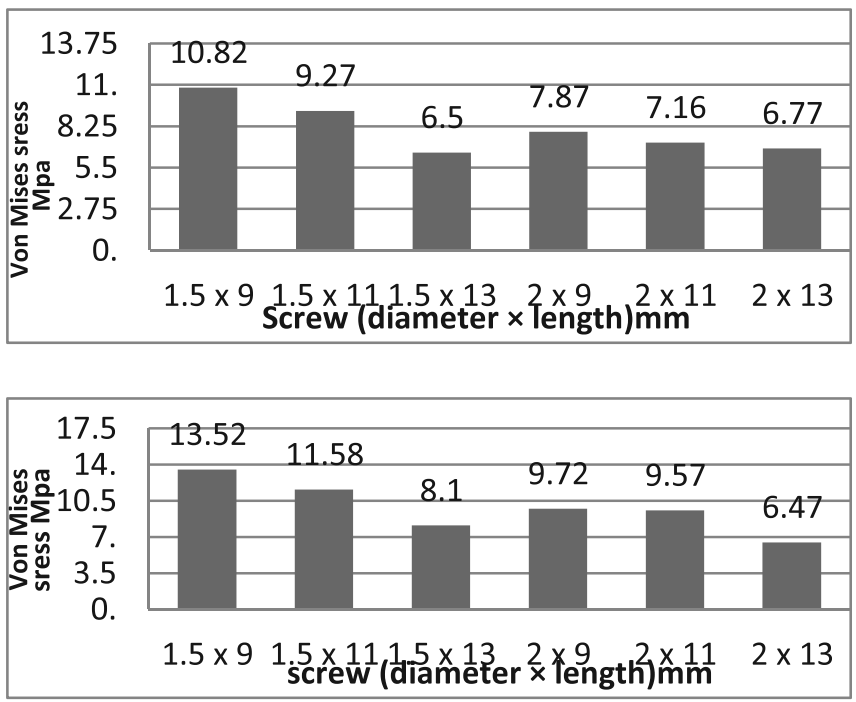
The Von Mises stresses in spongy bone in vertically inserted $2 \mathrm{~mm}$ diameter screws with 200gm and 250gm force were higher than those with $1.5 \mathrm{~mm}$ diameter screws as illustrated in figure 9 (a-b) respectively.
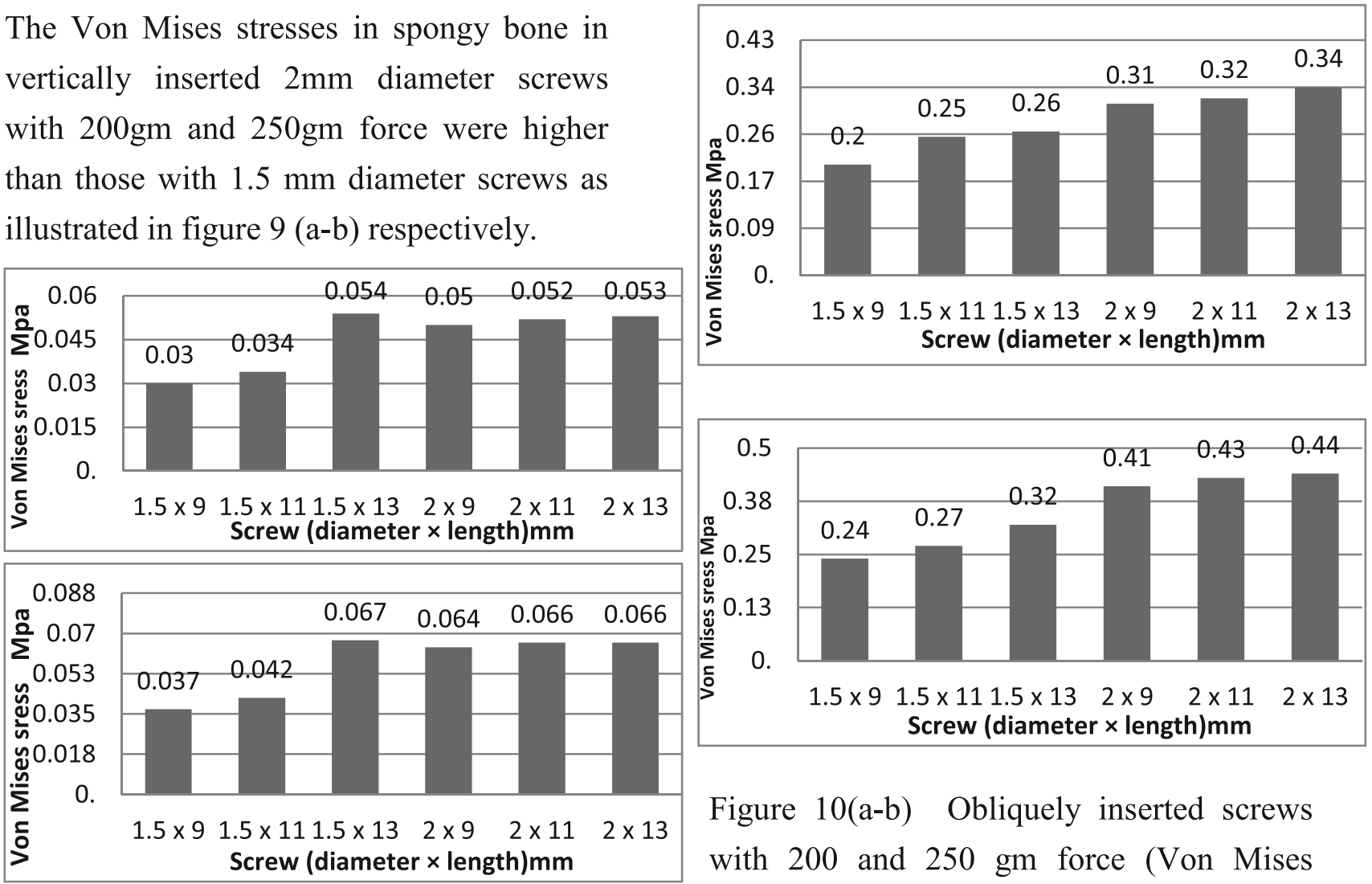

Figure 10(a-b) Obliquely inserted screws with 200 and $250 \mathrm{gm}$ force (Von Mises

Figure 9(a-b) Vertically inserted screws with 200 and $250 \mathrm{gm}$ force (Von Mises stresses) in spongy bone

The Von Mises stresses in the spongy bone in obliquely inserted 1.5 and $2 \mathrm{~mm}$ diameter screws with $200 \mathrm{gm}$ and $250 \mathrm{gm}$ force were higher with the $2 \mathrm{~mm}$ diameter screws as stress) in spongy bone

The maximum compressive stress and equivalent micro-strain in cortical bone was evident in run 23 with screw dimensions $13 \mathrm{~mm}$ length and $2 \mathrm{~mm}$ diameter under an oblique force magnitude of $250 \mathrm{gm}$ as shown in table 4. illustrated in figure $10(a-b)$ for Von Mises respectively. 
Table 4: The Maximum compressive stress and equivalent micro-strain in the cortical bone in oblique insertion both 200 and 250 gm force magnitudes

\begin{tabular}{|c|c|c|c|c|c|c|c|c|c|}
\hline \multicolumn{2}{|l|}{ Oblique } & \multirow{2}{*}{$\begin{array}{l}200 \\
\mathrm{gm}\end{array}$} & \multirow{2}{*}{$\begin{array}{l}\mathrm{S} 3 \\
\mathrm{MPa}\end{array}$} & S3 & \multicolumn{2}{|l|}{ Oblique } & \multirow{2}{*}{$\begin{array}{l}250 \\
\mathrm{gm}\end{array}$} & \multicolumn{2}{|l|}{ S3 } \\
\hline Diameter & Length & & & $\mu \varepsilon$ & Diameter & Length & & $\mathrm{MPa}$ & $\mu \varepsilon$ \\
\hline 1.5 & 9.0 & R14 & 13.06 & 940.3 & 1.5 & 9.0 & R13 & 16.33 & 1175.7 \\
\hline 1.5 & 11.0 & R16 & 12.81 & 921.6 & 1.5 & 11.0 & R15 & 15.29 & 1100.8 \\
\hline 1.5 & 13.0 & R18 & 7.4 & 532.8 & 1.5 & 13.0 & R17 & 9.39 & 676.1 \\
\hline 2.0 & 9.0 & R20 & 8.51 & 612 & 2.0 & 9.0 & R19 & 10.63 & 765.4 \\
\hline 2.0 & 11.0 & R22 & 32.19 & 2317.6 & 2.0 & 11.0 & R21 & 40.16 & 2887.2 \\
\hline 2.0 & 13.0 & R24 & 35.29 & 2534.4 & 2.0 & 13.0 & R23 & 44.11 & 3175.2 \\
\hline
\end{tabular}

\section{Discussion}

The success of mini-screws is influenced by factors; length, diameter and surface characteristics in addition to insertion angle and torque, force magnitude, anatomic location, soft-tissue characteristics, root proximity, and primary stability.

Increasing the diameter of mini-screws increases their primary stability more effectively than increasing their lengths. ${ }^{5}$ However, larger mini-screw diameter can limit the placement options due to root proximity. Thus, various tapered mini-screw designs have been proposed to solve this problem. A tapered mini-screw increases primary stability through induction of a controlled compressive force in the cortical bone. ${ }^{15}$ Howev- er, excessive insertion torque might lead to deformations of the surrounding bone that would cause congestion and necrosis at the bone interface. ${ }^{16}$ Increased deformation from excessive stress may increase inflammatory mediators to the site and result in bone resorption and remodeling, which in turn might cause mini-screw failure. ${ }^{9}$

In order to maximize the benefit of miniscrews applications, it is thus important that their mechanical variables become fully understood. However, the clinical environment proposes difficulty in determining the underlying biomechanical mechanisms for miniscrews via an experimental approach because of the limited measureable mechanical indices and imprecise parameter control. Hence, FEA can be a suitable method for 
estimating stresses and deformations exerted on mini-screws simulating real clinical situations.

FEA is a computer-based numerical simulation technique that is widely utilized for predicting the mechanical behavior of engineering structures, in addition to solving solutions for engineering problems. Based on their numeric origin, the investigated parameters can be controlled more specifically, and many mechanical indices can also be examined at any site on the model to reflect the rationale of a mechanical response.

The validity of three dimensional FEA is mainly dependent upon: 1) Similarity of the finite element model to the real structure to be analyzed since excessive simplifications in the geometry would inevitably lead to considerable inaccuracy. 2) Accurate and precise modeling of the material properties utilized in the case model. 3) Effectiveness of modeling to the boundary conditions.

In our study the model consisted of the following components: mini-screw, cortical and spongy bone. The dimensions of the mini-screws in our study were $1.5 \mathrm{~mm}$ and 2 $\mathrm{mm}$ in diameter, which were the most preferred and widely used diameters. ${ }^{14,17,19}$ According to Miyawaki et $\mathrm{al}^{3}$ the success rate of mini-screws increased from $0.0 \%$ to $83.9 \%$ with the diameter increase from 1.0 to $1.5 \mathrm{~mm}$.

The bone geometry in this study was simplified and simulated as a parallelogram composing both the cortical and spongy bone.
The dimensions for the cortical bone were (20mm length $\mathrm{m} 20 \mathrm{~mm}$ width $\times 2 \mathrm{~mm}$ high) whereas the spongy bone dimensions were (20mm length $\times 20 \mathrm{~mm}$ width $\times 13 \mathrm{~mm}$ high). These dimensions were based on the recommendations of Liu et al. ${ }^{20}$

The mini-screw solid modelling was created at the Autodesk Inventor Version (8) ${ }^{*}$. This software program provided more accurate simulation the exact mini-screw design, while in previous studies the mini-screw design was simulated directly in the ANSYS ${ }^{\dagger}$ environment software which had limited options in accurate design simulation operations. The subsequent operations which involved Boolean, osseointegration and boundary constrains were in accordance to Perilloet al. ${ }^{21}$

Pickard et al ${ }^{22}$ recommended a $45^{\circ}$ insertion angle for the mini-screws to the bone surface to creat a larger contact area between the cortical bone and the mini-screw. This will increase the placement torque, resulting in a positive effect on the mini-screw stability during orthodontic forces application. However, Joseph et al ${ }^{23}$ and Choi et $\mathrm{al}^{24}$ suggested that the $90^{\circ}$ insertion angle of mini-screws in order toavoid the setbacks of oblique insertion such as potentially creating longer lever arms and reducing the insertion depths inside the bone. Insertion at an oblique angle might cause slippage of the mini-screw during its first contact with the bone surface as well as microdamage of the cortical bone. 
In our study the increase in length for all the vertical mini-screw insertions with both 200 and $250 \mathrm{gm}$ of force magnitude had no effect on the deformation and Von Mises stress within the mini-screws. Similarly this was evident within the cortical and spongy bone. However, in case of oblique insertion the mini-screw length increase reduced Von Mises stresses generated within the miniscrew and cortical bone but increased the Von Mises stresses within the spongy bone. Therefore, the increase in mini-screw length can be considered more effective with oblique insertion this is concurrent with the findings of Choi et al. ${ }^{24}$ who concluded that the maximum von Mises stresses increased as insertion angle decreased during miniscrew. The stresses in cortical and spongy bone were lowest for mini-screws placed at $90^{\circ}$ to the bone surface, irrelevant of miniscrew design. This finding is consistent with the results of previous studies ${ }^{9,10}$ demonstrating that maximum von Mises stresses in mini-screws and cortical bone decreased as insertion angle increased. An analysis of stress distributions in cortical and spongy bone revealed that the stress was absorbed mostly by cortical bone, and small amount was transmitted to spongy bone. ${ }^{9}$

These finding were cited by Liu et al ${ }^{20}$ in their FEA study. They reported that the exposed length (the level arm of the bending moment) was the real factor influencing stress and displacement not the total length of the mini-screw so longer mini-screw might not provide extra stability if it cannot be implanted deeply enough to reduce the lever arm. In addition Lin et al. ${ }^{20}$ reported that the exposed lengths of mini-screws were significantly associated with cortical bone stress during force application. Neither orthodontic force direction nor the insertion angle affect cortical bone stress significantly. ${ }^{20}$

In our study the increase in mini-screw diameter from 1.5 to $2 \mathrm{~mm}$ with both 200 and $250 \mathrm{gm}$ force magnitudes in both vertical and oblique insertion of mini-screws decreased the deformations and stresses within the mini-screws and cortical bone. However, these mechanical properties increased in spongy bone. These findings were in agreement with Wilmes et al ${ }^{13}$ and Liu et al $^{20}$ who reported that increasing the mini-screw diameter was the mosteffective way to reduce the stress, hence increasing the stability and decreasing the failure rate.

Finally, it could be concluded that with both vertical and oblique insertions the pattern of deformations and stresses within the screw and cortical bone decreased with increase in length and diameter with both force magnitudes (200 and $250 \mathrm{gm}$ ). However the stress values within the cortical bone were higher in oblique insertion.

Our results were consistent withPerillo et al ${ }^{10}$ Woodall et al ${ }^{14}$ and Lee et al ${ }^{19}$ in their studies on cadaver and finite element model. They found that the anchorage resistance offered by screws inserted at $90^{\circ}$ to the alveolar process bone was greater than the anchorage resistance of screws inserted at $30^{\circ}$ or $60^{\circ}$. In addition to the cortical bone stress 
created via loading mini-screws inserted at $90^{\circ}$ was less than the bone stress created via loading mini-screws at either $30^{\circ}$ or $60^{\circ}$. They recommend insertion of the miniscrews perpendicular $\left(90^{\circ}\right)$ to the cortical bone as long as it did not risk root damage in order to take advantage of the improved biological and biomechanical stability when applying heavy forces.

Our results also supported the outcomes of Choi et al ${ }^{24}$ in which they designed a threedimensional maxilla model of a dentition with extracted first premolars and used 2 types of mini-screws (tapered and cylindrical) with $1.45 \mathrm{~mm}$ diameter and $8 \mathrm{~mm}$ length inserted at $30^{\circ}, 60^{\circ}$, and $90^{\circ}$ with respect to the bone surface. They concluded that both cylindrical and tapered mini-screw designs, perpendicular $90^{\circ}$ insertion to the bone surface is recommended to reduce stress in the surrounding bone and offer better anchorage.

The maximum stress (Von Mises) generated in the mini-screw and cortical bone in all the simulated finite element models in this study was 72.77 and 13.52 MPa respectively. Both of these values were well below the known yield stress of titanium (692 MPa) and cortical bone $(200 \mathrm{MPa})$ respectively. ${ }^{25}$ Therefore, it can be concluded that mini-screws and cortical bone had sufficient strength to withstand force magnitudes up to $250 \mathrm{mg}$.

Frost ${ }^{26}$ noted that if the peak strain exceeded 4000 micro-strain, the structural integrity of the bone was threatened leading to pathologic overload and micro-damage accumulation with subsequent bone resorption and reduc- tion of bone strength, resulting to miniscrews loosening.

In the current study the concept of microstrain was considered. The maximum stress value at the cortical bone was observed with the oblique insertion of mini-screws. This value (44.1 $\mathrm{MPa}$ ) was equivalent to 3175.2 micro-strain. This calculated value was well below the physiologic limit (4000 microstrain) of bone integrity. Therefore, it can be concluded that the FEA utilized in our study is a useful tool to estimate the force effect on stress distribution and predict the tissue reaction against the orthodontic and orthopedic force.

There are limitations in this study that must be taken into consideration when interpreting the data. The cortical bone thickness of model was selected according to previous studies. ${ }^{20,27} \mathrm{~A}$ cortical bone. thickness of $1.5 \mathrm{~mm}$ was utilized to simplify model construction. Whereas the peri-screw area exhibits anisotropy and heterogeneity during physiological conditions, this study was performed with an isotropic and homogeneous model that considered physical features only.

\section{Conclusions}

- Increase in the miniscrew diameter with both vertical and oblique insertion reduced the deformations and stresses within the miniscrew and cortical bone but increased the deformations and stresses within the spongy bone. 
- Increase in the miniscrew length with vertical insertion had negligible effect. However, in oblique insertion it reduced the deformations and stresses within the miniscrew and cortical bone but increased the deformations and stresses within the spongy bone.

- The deformation and stress values within the cortical bone were higher in oblique insertion than vertical insertion with both (200 and $250 \mathrm{gm}$ ) force.

- The maximum stress (Von Mises) generated in the miniscrew and cortical bone were below the yield stress of pure titanium and cortical bone. Therefore, the miniscrews and cortical bone had sufficient strength to withstand force magnitudes up to $250 \mathrm{gm}$.

- The maximum value of calculated microstrain on the cortical bone was well below the physiologic limit of bone integrity.

\section{References}

1. Reynders R, Ronchi L, Bipat S. Mini-implants in orthodontics: a systematic review of the literature. Am J OrthodDentofacialOrthop 2009;135:564.

2. Cha JY, Hwang CJ, Kwon SH, Jung HS, Kim KM, Yu HS. Strain of boneimplant interface and insertion torque regarding different miniscrew thread designs using an artificial bone model. Eur J Orthod 2015;37:268-74.
3. Miyawaki S, Koyama I, Inoue M, Mishima K, Sugahara T, TakanoYamamoto T. Factors associated with the stability of titanium screws placed in the posterior region for orthodontic anchorage. Am J OrthodDentofacialOrthop 2003;124:373-8.

4. Park HS, Jeong SH, Kwon OW. Factors affecting the clinical success of screw implants used as orthodontic anchorage. Am J OrthodDentofacialOrthop 2006;130:18-25.

5. Lim SA, Cha JY, Hwang CJ. Insertion torque of orthodontic miniscrews according to changes. in shape, diameter and length. Angle Orthod 2008;78:234-40.

6. Katić V, Kamenar E, Blažević D, Špalj S. Geometrical design characteristics of orthodontic mini-implants predicting maximum insertion torque. Korean J Orthod 2014;44:177-83.

7. Choi SH, Cha JY, Joo UH, Hwang CJ. Surface changes of anodic oxidized orthodontic titanium miniscrew. Angle Orthod 2012;82:522-8.

8. Cho YC, Cha JY, Hwang CJ, Park YC, Jung HS, Yu HS. Biologic stability of plasma ion-implanted miniscrews. Korean J Orthod 2013;43:120-6.

9. Jasmine MI, Yezdani AA, Tajir F, Venu RM. Analysis of stress in bone and microimplants during en-masse retraction of maxillary and mandibular anterior teeth with different insertion angulations:a 3- 
dimensional finite element analysis study. Am J OrthodDentofacialOrthop 2012;141:71-80.

10. Perillo L, Jamilian A, Shafieyoon A, Karimi H, Cozzani M. Finite element analysis of miniscrew placement in mandibular alveolar bone with varied angulations. Eur J Orthod 2015;37:56-9.

11. Kyung HM, Park HS, Bae SM, Sung JH, Kim IB. Development of orthodontic micro-implants for intraoral anchorage. $\mathrm{J}$ ClinOrthod 2003;37:321-8; quiz 314.

12. Zha-

oL,XuZ,WeiX,ZhaoZ,YangZ,ZhangL,et al. Effect of placement angle on the stability of loaded titanium microscrews: a microcomputed tomographic and biomechanical analysis. Am J OrthodDentofacialOrthop 2011;139:628-35.

13. Wilmes B, Su YY, Drescher D. Insertion angle impact on primary stability of orthodontic mini-implants. Angle Orthod 2008;78:1065-70.

14. Woodall N, Tadepalli SC, Qian F, Grosland NM, Marshall SD, Southard TE. Effect of miniscrew angulation on anchorage resistance. Am J OrthodDentofacialOrthop 2011;139:e147-52.

15. Yoo SH, Park YC, Hwang CJ, Kim JY, Choi EH, Cha JY. A comparison of tapered and cylindrical miniscrew stability. Eur J Orthod 2014;36:557-62.

16. Ueda M, Matsuki M, Jacobsson M, Tjellström A. Relationship between inser- tion torque and removal torque analyzed in fresh temporal bone. Int J Oral Maxillofac Implants 1991;6:442-7.

17. Holma L, Cunninghamb S, Petriec A, Cousleyd R. An in vitro study of factors affecting the primary stability of orthodontic mini-implants Angle Orthod. 2012; 82:1022-1028.

18. Lin T, Tsai F, Chen C, and Lin L. Factorial analysis of variables affecting bone stress adjacent to the orthodontic anchorage mini-implant with finite element analysis. Am J OrthodDentofacialOrthop 2013; 143:1829.

19. Lee J, Kim JY, Choi YJ, Kim $\mathrm{KH}$, Chung CJ. Chung. Effects of placement angle and direction of orthopedic force application on the stability of orthodontic miniscrews. Angle Orthod. 2013; 83:667-673.

20. Liu $\mathrm{T}$, Chang $\mathrm{C}$, Wong $\mathrm{T}$ and Liu J. Finite element analysis of miniscrew implants used for orthodontic anchorage. Am J OrthodDentofacialOrthop 2012; 141:468-76.

21. Perillo L, Jamilian A, Shafieyoon A, Karimi $\mathrm{H}$ and Cozzani M. Finite element analysis of miniscrew placement in mandibular alveolar bone with varied angulations. Eur J Orthod (2015) 37 (1): 56-59.

22. Pickard MB, Dechow, Rossouw PE, Buschang PH. Buschang Effects of 
miniscrew orientation on implant stability and resistance to failure. Am J OrthodDentofacialOrthop 2010;137:91-9.

23. Joseph S. Petrey, Marnie M. Saunders, G. Thomas Kluemper, Larry L. Cunningham and Cynthia S. Beeman. Temporary anchorage device insertion variables: effects on retention. Angle Orthod. 2010;80:634-641.

24. Choi S, Kim S, Lee K, Sung S, and Chun Y, Hwang C. Stress distributions in peri-miniscrew areas from cylindrical and tapered miniscrews inserted at different angles. Korean J Orthod 2016; 46(4):189-198.
25. Duaibisa R, Kusnotob B, Natarajanc R, Zhaod L, Evanse C. Factors affecting stresses in cortical bone around miniscrew implants A threedimensional finite element study. Angle Orthod. 2012;82:875-880.

26. Frost H. A 2003 update of bone physiology and Wolff's law for clinicians. Angle Orthod. 2004; 74:3-15.

27. Deguchi T, Nasu M, Murakami K, Yabuuchi T, Kamioka H, TakanoYamamoto T. Quantitative evaluation of cortical bone thickness with computed tomographic scanning for orthodontic implants. Am J OrthodDentofacialOrthop 2006;129:721.e7-12. 